Digital Press Social Sciences and Humanities

Effect of Mindful Parenting Program in Reducing

Psychological Burden on Mother with Cerebral Palsy Children

I Rai Hardika and Sofia Retnowati

Proceeding of The 10th International Conference of Indigenous and Cultural

Psychology 2019

Kwartarini Wahyu Yuniarti, Donald H. Saklofske, Rosnah Ismail, Saadi Lahlou (eds) 


\title{
Effect of Mindful Parenting Program in Reducing Psychological Burden on Mother with Cerebral Palsy Children
}

\author{
I Rai Hardika ${ }^{1, *} \&$ Sofia Retnowati ${ }^{2}$ \\ 1 Faculty of Health Science and Technology, Dyana Pura University, Bali, Indonesia \\ 2 Faculty of Psychology, Gadjah Mada University, Yogyakarta, Indonesia \\ *e-mail: i.rai.hardika@undhirabali.ac.id
}

\begin{abstract}
Caring children with cerebral palsy might rise the potential of having physical, emotional, and psychological burdens for the mother. Mindfulness-based interventions can help to decrease psychological distress, sleep disturbances, and physical fatigue by improving the growth of quality of life and spirituality. The purpose of this study is to discover the effect of a mindful parenting program in reducing the psychological burden of the mother's children with cerebral palsy. This research uses the one-group pre-test post-test design using a double pre-test. Measurement of psychological burden using psychological burden scale. The participants are 6 mothers of the cerebral palsy children who followed 8 sessions mindful parenting program. Hypothesis testing using the Wilcoxon-signed-rank test along with qualitative data analysis using observation and self-report. The results showed that mindful parenting program significantly decreased psychological burden on mothers with cerebral palsy children with $\mathrm{z}=$ $2.201(p=0,028 ; p<0,05)$. The effect of a mindful parenting program on psychological burden reduction was $63 \%(r=-0.63)$.
\end{abstract}

\section{Keywords}

cerebral palsy, mindful parenting, mother, psychological burden

\section{Introduction}

The birth of a child in a healthy condition is the expectation of every parent. But in fact, not all children are born with normal and health conditions, some of them have disabilities. According to WHO, disability is a condition marked by some or almost all parts of the human body experiencing temporary or permanent disruption so as to enable increased difficulty in body function along with increasing age (WHO, 2011). Based on the same source, disability refers to two aspects. First, the interaction between individuals with health conditions such as cerebral palsy, down syndrome, and depression. Second, the interaction aspects of personal and environmental factors such as social responses with negative attitudes, difficulty in accessing transportation, and the limitations of social support. In line with that information, one type of disability is cerebral palsy (Centers for Disease Control and Prevention, 2014).

Research on cerebral palsy has a long history by Sigmund Freud (1893) and Little William (1843) who named cerebral palsy with the term Little Disease (Morris, 2007). Cerebral palsy is described as a disorder of the development of motion and permanent posture that appears during the infancy or in early childhood because of a non-progressive disorder of the brain. Children with cerebral palsy have damage in the formation of one or most parts of the brain which is causing impaired motion control (Bajraszewski et al., 2008). This disorder occurs before, during, or immediately after birth, leading to limitations in activities (Berker, Yalçın, \& Global HELP (Organization), 2010; Colver, Fairhurst, \& Pharoah, 2014; Rethlefsen, Ryan, \& Kay, 2010).

Risk factors associated with cerebral palsy are grouped into prenatal, perinatal, and postnatal factors (Berker et al., 2010). A child with cerebral palsy has a variety of motor disorders as well as other comorbid disorders associated with lesions in the brain (Bax et al., 2005). There are three types of motor problems experienced by children with cerebral palsy, namely primary disorders, secondary disorders, and tertiary disorders (Berker et al., 2010). Motor disorders characterized by abnormal muscle control, movement, and posture, and spasticity (Colver et al., 2014; Morris, 2007; Richards \& Malouin, 2013). Motion aids are used to help mobility (Beckung et al., 2008; Elliott \& Shewchuk, 2004). 
Children with cerebral palsy experience other intercurrent disorders such as perceptual disorders, cognition, communication, behavior, and musculoskeletal problems of pain and pain in the body due to muscle, joint, tendon, ligament, and nervous disorders (Colver et al., 2014; Rosenbaum et al., 2007). These disorders will be experienced by cerebral palsy children in their life. These conditions cause them to tend to depend on others in doing various activities. The higher severe level of cerebral palsy, make more children with cerebral palsy needs help from others (Bottcher, 2010; Ribeiro et al., 2014; Zaretsky, Richter, \& Eisenberg, 2005). The existence of a child with cerebral palsy in a family will create pressures and challenges (Alaee et al., 2015; Elliott \& Shewchuk, 2004). Caring child with cerebral palsy will have an impact on physical, social, mental health, financial and family freedoms (Brehaut et al., 2009; Davis et al., 2010; Grootenhuis \& Bronner, 2009; Olawale, Deih, \& Yaadar, 2013; Park et al., 2011). The ability of coping, self-control, togetherness, and cohesiveness in the family becomes decisive in the face of stressful conditions when parenting cerebral palsy (Glenn et al., 2009; Raina, 2005). Parent is a family member who will be a natural caregiver for the child with cerebral palsy. Parents who have children with cerebral palsy have a greater risk of stress caring than those with normal children (Woodgate, Edwards, \& Ripat, 2012).

Parent's role especially who assist the child with cerebral palsy has a difference between father and mother. One of the differences is the existence of responsibility in care (Raina, 2005). Mother is the figure who became the primary caregiver for the child's cerebral palsy (Alaee et al., 2015; Ones, 2005). This condition is similar to the research which states that mothers have a responsibility to provide constant and exclusive care. The limitations of the mother to fulfill such responsibilities often make the mother fail to care for themselves, children, and even the family (Mendenhall \& Mount, 2011).

Mothers with children who are diagnosed with cerebral palsy show their emotional responses angry, sad, embarrassed, fearful, and guilty because of the expectations that do not match with the reality, having a healthy and perfect child (Barnett et al., 2003; Fernández-Alcántara et al., 2015). This condition is in line with the results of research that states mothers of cerebral palsy children feel helpless, overwhelmed and frightened in the face of parenting cerebral palsy so that they often questioned themselves about ability in parenting and feeling guilty about the inability (Rojahn, Schroeder, \& Hoch, 2008). Based on the circumstances, this study focuses more on mothers of children with cerebral palsy.

The psychological burden in nurturing leads to a multidimensional response to the physical, psychological, emotional, social, and financial stress associated with parenting experiences (Kasuya, Polgar-Bailey, \& Takeuchi, 2000). The concept of psychological burden is distinguished between objective burdens that refer to changes in everyday household life from caregivers because of the nurturing process and subjective burden referring to emotional attitudes and reactions to experience in parenting (Myers, 2003). Zarit, Reever, and Bach-Peterson define the burden as the impact of parenting that is owned by the primary caregiver. The impact is seen to the extent to which the caregiver sees that the various areas of his life that include social life, recreation, health, and also privacy have been influenced by his parenting duties (Muñoz-Marrón et al., 2013).

Several studies have proven to reduce the psychological burden. Psychoeducation programs reduce the psychological burden on caregiver Alzheimer (Martín-Carrasco et al., 2009), reduce the burden of depressed families (Prisco et al., 2012), and reduce the psychological burden of the family caregiver diabetes mellitus (Ambarawati, 2015). Intervention-based cognitive-behavioral approaches can reduce the burden of care on Alzheimer's families (Marriott, 2000). Treatment of forgiveness decreases the subjective burden of the schizophrenic caregiver family (Koeswardani, 2011). Psychosocial interventions through coping strategies training reduce the burden of dementia caregivers (Chen et al., 2015). Mindfulness-based interventions decrease psychological pressure (burdened symptoms), sleep disturbances, and physical fatigue in caregiver cancer patients (Carlson, Rouleau, \& Garland, 2015).

Mindfulness is conceptualized as the attitude of individual consciousness to the state of himself. These conditions include serious attention and non-evaluative alertness from internal and external experiences (Brown \& Ryan, 2003; Brown, Ryan, \& Creswell, 2007). Characteristics of mindfulness include pure consciousness, non-conceptual consciousness, focusing attention, evaluation of pure sensory experiences, current orientation, and consciously aware of transitions such as the transition between the inner self and the outside world (Brown et al., 2007). Kabat-Zinn explains that mindfulness is a state of uninterrupted attention over a period of time accompanied by no critical assessment of the physical, cognitive, and ongoing psychological experiences (Kabat-Zinn, 2005, 2013). Mindfulness can be enhanced by meditation or mindfulness attitude training (Baer, 2003; Carmody \& Baer, 2008).

Applying a mindfulness attitude into parenting is one application of mindfulness. Mindful parenting is a program for parents in applying the mindfulness skills/attitude to themselves and their experiences in caring for children (Bögels \& Restifo, 2014). Kabat-Zinn defines mindful parenting as an ongoing creative 
process so it is not an endpoint (Bögels \& Restifo, 2014; Pakdaman, 2014). These conditions include realizing the internal processes of mind, emotions, and sensations of the body, as well as the external processes which are child, family, home, and the wider culture.

The mindful parenting program in this study is an adaptation of the Mindful Parenting module: A Guide for Mental Health Practitioners (Bögels \& Restifo, 2014), compiled with fellow researchers (Rizky, 2017). The researchers modified the activities based on the theme of each session and adjusted to the objectives and needs of the study. The program consists of eight main sessions. The researcher modifies it by giving one additional session as an opening. This opening session serves as a medium to explain the implementation of a mindful parenting program to participants. Implementation of a mindful parenting program in this research used a group therapy approach. Figure 1 illustrates the framework of this study.

The aims of this study to help mothers of children with cerebral palsy reduce psychological burden by using a "mindful parenting" program. The hypothesis of this study is a "mindful parenting" program can reduce the psychological burden on mothers who have children with cerebral palsy.

\section{Methods}

\subsection{Participants}

Participants of this study were 6 mothers with cerebral palsy children. The inclusion criteria (a) mother of a child with cerebral palsy aged 5-15 years, (b) primary caregiver of the child and lives with the child, (c) able to mobilize sufficiently to join groups, (d) able to speak Indonesian well and correctly both verbally and in writing, (e) have a cellphone number that can be contacted for the research process. The selection of participants used a convenience sampling technique.

\subsection{Materials and Tools}

\subsubsection{Preparation}

The materials and tools employed in this study were the following. First, the Mindful parenting module is an adaptation and modification of the mindful parenting module: A Guide for Mental Health Practitioners (Bögels \& Restifo, 2014). Preparation of the mindful parenting module was conducted in conjunction with the research colleagues. Preparation was conducted by doing the translation to the Indonesian language then formulate the purpose of module preparation. Second, Scale of psychological burden uses the Zarit Caregiver Burden Scale modification developed by John, Hennessy, Dyeson, and Garrett (2001). Third, Measurement tools for manipulation check for Mindful Parenting scale uses the Interpersonal Parenting (IEM-P) scale modification developed by Duncan (2007). Fourth, the Behavior checklist compiled by the researchers using the degree of self-report assessment range of participants about the characteristics of psychological burden and the implementation of skills mindful parenting. Fifth, Observation Sheets for the researcher and the therapist used observational guidance and successful indicators to examine the participants process in each season. This study involved three observers. Sixth, Material Books recorded instruction to guide participant do their homework independently and behavioral checklist.

\subsubsection{Testing}

Mindful parenting module instrument was validated by 4 judgment experts who meet the criteria of a psychologist and has experience as a mindfulness practitioner. The result of Aiken's V showed that V value average of 0.90 , it can be concluded that the mindful parenting module has good content validity. The experimental correlation coefficient of expert judgment for module obtained 0.973 which can be interpreted have a very good correlation. Consistency of one rater has a coefficient of 0.830 which can be interpreted very well (Wongpakaran et al., 2013).

Both psychological burden scale and mindful parenting scale were validated by 25 expert judgments who are professional psychologists who have taken psychology-scale courses. The result of Aiken's V showed that $\mathrm{V}$ value for psychological burden scale average 0.84 , and $\mathrm{V}$ value for mindful parenting scale average 0.82 . The result can be concluded that both psychological burden scale and mindful parenting scale has good content validity. 
Testing was conducted to measure reliability. Instrument test is conducted to participants who have criteria approaching the criteria with the research participants in the boundaries of mothers with children with special needs. The scale trial was applied to 98 respondents residing in the location of hospital A, autism B service center, and parent community with cerebral palsy children at extraordinary school C. Differential power analysis among items considered for a satisfying result is in correlation coefficient $\geq 0,25$ (Azwar, 2012). The result correlation coefficient psychological burden scale from 0.277 to 0.499 and correlation coefficient mindful parenting scale from 0.256 to 0.629 . The result can be concluded that both psychological burden scale and mindful parenting scale has a good correlation. The suggested value of Cronbach's Alpha $(\alpha)$ is at $\alpha>0.60$ (Azwar, 2011). Cronbach's Alpha values of mindful parenting scale and psychological load scale are 0.714 and $0.8 \alpha>0.60$ which means the internal consistency of all items is good

Module testing was conducted with 5 maternal participants with special needs children. The trial produced several evaluations regarding the module usage process. The evaluation was obtained from facilitators, observers, and participants. The researcher conducted an analysis by Wilcoxon Signed Rank Test $\mathrm{Z}=-2.023$ and $0.043(\mathrm{p}<0.05)$ based on data resulting in the check manipulation scale (mindful parenting). The result can be concluded which showed a significant difference between mindful parenting measurement before and after group Mindful Parenting Program with the trial or pilot participant.

\subsubsection{Implementation Intervention}

Selection subjects are done by providing information on parenting mindful activities in foundations, communities, and hospitals as well as parents of children with cerebral palsy that the researchers met independently. The researcher used the flyer as the instrument to provide information. There are 6 mothers who declared their willingness to be participants in this study.

The implementation phase of this research intervention consisted of nine sessions consisting of one opening session and eight main sessions. The eight sessions are divided into four meetings for 2 weeks to 1 month. Each meeting has a duration of 180 - 240 minutes with a break of 60 minutes. Each session is implemented based on the mindful parenting program module that has been prepared by the researcher. Stages of implementation of interventions conducted by researchers presented in Table 1. The following module design mindful parenting used by researchers presented in Table 2.

Table 1 Stages of intervention implementation

\begin{tabular}{ll}
\hline \multicolumn{1}{c}{ Phase } & \multicolumn{1}{c}{ Instrument } \\
\hline Pre-test 1 & Flyer, psychological \\
& burden scale \\
& Informed consent, \\
& psychological burden \\
scale, mindful & parenting scale \\
Pre-test 2 & Mindful parenting \\
& module, activity \\
& notebook, material \\
& book, sheet of behavior \\
& checklist, recording \\
& instruction, evaluation \\
& sheet, observer \\
Intervention & observation sheet \\
& Psychological burden \\
& scale, mindful \\
& parenting scale. \\
\hline
\end{tabular}

Implementing the Intervention: First, a clinical psychologist who has been a researcher and is experienced in guiding group therapy. Second, three observers, with qualifications as a student of the Faculty of Psychology, as having passed the course on psychodiagnostics (observation, interview), and having technical training on the observation therapy process. 


\subsection{Research Design}

This study used a quasi-experiment approach with pre-test post-test designs using a double pre-test

(Shadish, Cook, \& Campbell, 2002). Fig. 1 show this experiment design.

$01 \quad 02 \quad \mathrm{X} \quad 03$

Fig. 1 Experiment Design

Note: 01 (pre-test 1), 02 (pre-test 2), X (mindful parenting treatment), 03 (post-test)

\begin{tabular}{|l|l|}
\hline Cerebral palsy child problems \\
\hline$-\quad$ Independence (limited physical ability) \\
- & Disorders of cognitive abilities (learning), emotions (unstable) and social (limited interaction) \\
\hline
\end{tabular}

\begin{tabular}{|ll|}
\hline & Mindful Parenting Program \\
\hline a. & Automatic Parenting \\
b. & Beginner's mind in Parenting \\
c. & Reconnect with the body as a Parent \\
d. & Respond vs React \\
e. Parenting Patterns \\
f. Parenting conflict \\
g. Love and Limitations \\
h. The path of awareness through \\
\end{tabular}$$
\Rightarrow
$$

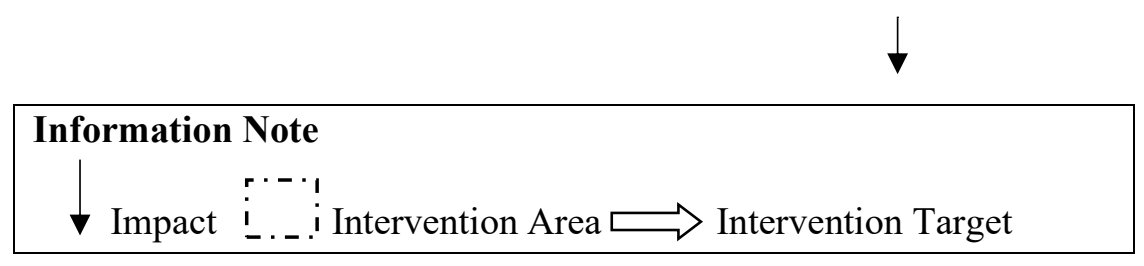

The impact of the problem of cerebral palsy children on Mother

- Decreased physical health (lack of rest)

- Financial problems (low working time)

- Social (lack of support and relationship with the environment)

- Psychological (stress that leads to psychological burden)

Mindfulness skills
patience, looking with a
beginner's attitude,
fostering trust, undergoing
a process (without
ambition), practicing
acceptance of the situation,
and letting go (releasing
the attachment of thoughts,
feelings, and experiences).

\begin{tabular}{|l|}
\hline Mother's psychological burden is reduced \\
\hline Role conflict [communication and two-way \\
relations] \\
Negative feeling [ Gratitude, accept whatever \\
the condition] \\
Inability [ Confident with ability, do the best] \\
Guilt [Live it openly]
\end{tabular}

Fig. 2 Framework of the study 
Table 2 Mindful parenting module design

\begin{tabular}{|c|c|c|c|}
\hline Meetings / Sessions & Theme & Activities & Time \\
\hline $\begin{array}{l}\text { Meeting } 1 \\
\text { (Opening) }\end{array}$ & $\begin{array}{l}\text { Introduction and } \\
\text { technical } \\
\text { information }\end{array}$ & $\begin{array}{l}\text { Psychoeducation of } \\
\text { mindfulness and } \\
\text { mindful parenting, } \\
\text { general introduction, } \\
\text { modality for } \\
\text { practice, technical } \\
\text { implementation of } \\
\text { mindful parenting } \\
\text { program. }\end{array}$ & 120 minutes \\
\hline \multirow[b]{2}{*}{$\begin{array}{l}\text { Meeting } 2 \\
(1 \& 2)\end{array}$} & $\begin{array}{l}\text { Be aware of } \\
\text { automatic parenting }\end{array}$ & $\begin{array}{l}\text { Listening practice, } \\
\text { talking and eating } \\
\text { consciously, and } \\
\text { body scan }\end{array}$ & 90 minutes \\
\hline & $\begin{array}{l}\text { Observe a child with } \\
\text { a beginner's mind }\end{array}$ & $\begin{array}{l}\text { Practice of seeing } \\
\text { consciously, the } \\
\text { practice of } \\
\text { thanksgiving } \\
\text { meditation, the } \\
\text { practice of breathing } \\
\text { meditation }\end{array}$ & 90 minutes \\
\hline \multirow[b]{2}{*}{$\begin{array}{l}\text { Meeting } 3 \\
(3 \& 4)\end{array}$} & $\begin{array}{l}\text { Be aware of body } \\
\text { sensations when } \\
\text { parenting }\end{array}$ & $\begin{array}{l}\text { Practice meditation } \\
\text { sitting by observing } \\
\text { the breath and body } \\
\text { reaction, breathing } \\
\text { space practice } 3 \\
\text { minutes }\end{array}$ & 90 minutes \\
\hline & $\begin{array}{l}\text { Be aware of the } \\
\text { body's stress } \\
\text { response when } \\
\text { parenting }\end{array}$ & $\begin{array}{l}\text { Practice meditation } \\
\text { sitting by observing } \\
\text { the breath, the body } \\
\text { reactions, thoughts } \\
\text { and feelings that } \\
\text { arise, the } \\
\text { imagination } \\
\text { experience of } \\
\text { parenting stress, } \\
\text { breathing space } \\
\text { practice } 3 \text { minutes }\end{array}$ & 90 minutes \\
\hline Meeting 4 (5 \& 6) & $\begin{array}{l}\text { Be aware of } \\
\text { parent and child } \\
\text { conflict }\end{array}$ & $\begin{array}{l}\text { Psychoeducation of } \\
\text { the meditation } \\
\text { pattern response to } \\
\text { meditation practice } \\
\text { by observing } \\
\text { emotions, the } \\
\text { practice of walking } \\
\text { meditation. } \\
\text { Meditation } \\
\text { breaks, } \\
\text { imagination } \\
\text { improves conflict }\end{array}$ & 90 minutes \\
\hline \multirow{2}{*}{ Meeting 5 (7 \& 8) } & $\begin{array}{l}\text { Realize affection and } \\
\text { Limitations }\end{array}$ & $\begin{array}{l}\text { Practice of loving } \\
\text { kindness, } \\
\text { recognizing the } \\
\text { needs of the self as a } \\
\text { parent, reflects on } \\
\text { the story of two } \\
\text { wolves }\end{array}$ & 90 minutes \\
\hline & $\begin{array}{l}\text { Reflections on the } \\
\text { experience gained }\end{array}$ & $\begin{array}{l}\text { Body scans, grateful } \\
\text { meditation practices, } \\
\text { sharing processes } \\
\text { that have been } \\
\text { obtained using } \\
\text { symbols. }\end{array}$ & 90 minutes \\
\hline
\end{tabular}




\subsection{Analysis}

The use of a double pre-test aims to reduce the threat of maturity and regression. Changes caused by maturity before treatment can only be known by doing more than one pre-test (Knapp, 2016; Marsden \& Torgerson, 2012).

Data analysis was both quantitative and qualitative. Quantitative data analysis employed the Wilcoxon signed-rank test. The qualitative analysis employed descriptive results of other supporting data like observation checks in each session and self-report from the participant. The Wilcoxon signed-rank test performed two comparative tests. First, the comparative test between pre-test 1 and pre-test 2, the expected result is no different. Second, the comparative test between pre-test 2 and post-test of expected results is different. This combination as part of the statistical calculations in concluding the research hypothesis that the change of research subjects occurred after treatment (Knapp, 2016).

\section{Result}

\subsection{Quantitative Analysis}

Hypothetical testing was conducted by using the non-parametric with Wilcoxon signed-rank test showed that mindful parenting program is significantly able to reduce the psychological burden on mother with child cerebral palsy with $\mathrm{z}=-2.201(\mathrm{p}=0.028 ; \mathrm{p}<0.05)$. Table 3 shows scores and averages of psychological burden scales. Table 4 helps to explain that psychological burden scale measurement results pre-test 1 and pre-test 2 there is no significant difference. The significant difference is in the measurement result of pre-test 2 and post-test. Fig. 3 showed the score of psychological burden decreased in measurement.

Table 3 Scores and averages of psychological burden scales

\begin{tabular}{cccc}
\hline Name & pre-test 1 & pre-test 2 & posttest \\
\hline TH & 64 & 66 & 47 \\
RH & 62 & 63 & 31 \\
AW & 48 & 39 & 26 \\
IN & 48 & 41 & 30 \\
PT & 53 & 47 & 25 \\
MN & 55 & 60 & 27 \\
Average & 55 & 52.7 & 31 \\
\hline
\end{tabular}

Table 4 Psychological burden scale measurement results

\begin{tabular}{cccc}
\hline Phase & Average & Z score & $(\mathrm{p})$ \\
\hline First & 2,3 & $-0,943$ & 0,$345 ; \mathrm{p}>0,05$ \\
Second & 21,7 & $-2,201$ & 0,$028 ; \mathrm{p}<0,05$ \\
\hline
\end{tabular}

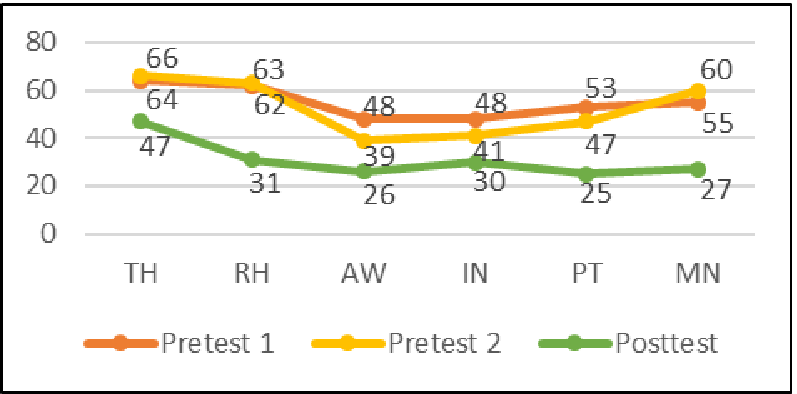

Fig. 3 Psychological burden scores each participant 
Influence given mindful parenting program is known through effect size. The effect size is measured using a $z$ score that can estimate the effect size ( $r$ ) by the formula $r=\frac{z}{\sqrt{\mathbb{N}}}$ (Field, 2009). $r$ mindful parenting $=\frac{\mathrm{z}}{\sqrt{\mathrm{N}}}=\frac{-2,201}{\sqrt{12}}=-0.63$. The coefficient of 0.63 shows the mindful parenting program having an effect of $63 \%$ on the decrease of psychological burden.

The researcher calculates each aspect on the psychological burden scale. The aspects are Role Conflict (RC), Negative Feelings (NF), Caregiver Efficacy (CE), and Guilt (G). The measurement result of each aspect of the psychological burden in pre-test 2 and post-test showed a significant decrease in all aspects after treatment. Table $\mathbf{5}$ helps to explain the significance.

Table 5 Result of each aspect in the psychological burden

\begin{tabular}{cccc}
\hline Aspect & Average & Z score & $(\mathrm{p})$ \\
\hline $\mathrm{RC}$ & 9,4 & $-2,207$ & 0,$027 ; \mathrm{p}<0,05$ \\
$\mathrm{NF}$ & 3,6 & $-2,214$ & 0,$027 ; \mathrm{p}<0,05$ \\
$\mathrm{CE}$ & 5,2 & $-2,207$ & 0,$027 ; \mathrm{p}<0,05$ \\
$\mathrm{G}$ & 2,9 & $-2,032$ & 0,$042 ; \mathrm{p}<0,05$ \\
\hline
\end{tabular}

For the manipulation check, after the hypothesis test, described above, researchers then analyzed the differences in mindful parenting scale scores as a manipulation check. Table 5 showed measurement in each aspect in mindful parenting scale. Fig. 4 showed score mindful parenting increased in measurement.

Table 6 Participant mindful parenting scale scores

\begin{tabular}{ccc}
\hline Name & Pre-test 2 & Post-test \\
\hline TH & 19 & 26 \\
RH & 26 & 29 \\
AW & 25 & 30 \\
IN & 25 & 28 \\
PT & 24 & 29 \\
MN & 21 & 25 \\
Average & 23,3 & 27,8 \\
\hline
\end{tabular}

The result of measuring the mindful parenting scale shows an average score difference of 4.5 points between the first measurement (pre-test $2=23.3$ ) with the second measurement (post-test $=27.8$ ). Wilcoxon signed-rank test analysis showed significant improvement of mindful parenting after treatment with $\mathrm{z}=-\mathbf{2 . 2 1 4}(\mathrm{p}=0.027 ; \mathrm{p}<0.05)$.

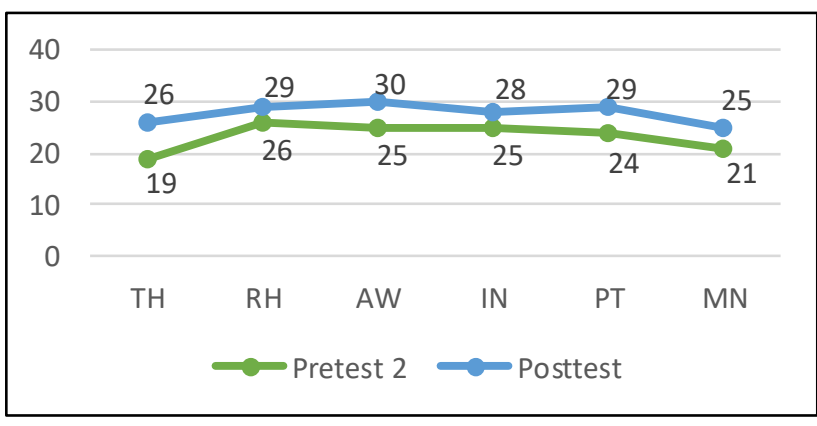

Fig. 4 Mindful parenting scores each participant

\subsection{Qualitative Analysis.}

The qualitative analysis here explains the intervention's actual process and supports the quantitative data, based on researcher observations sheets, self-report sheets, daily notes, face-to-face assignments, 
house assignments, and intervention evaluations by participants. Overall, the intervention process ran smoothly based on the schedule. Material Books and Recorded instruction can help participant do their homework independently. Participant meets the inclusion criteria which showed in Table 7 for demographic information (age of children).

Table 7 Demographic information

\begin{tabular}{ccccc}
\hline No & Name & Age & $\begin{array}{c}\text { Status / Number } \\
\text { of children }\end{array}$ & Age of children \\
\hline 1 & TH & 32 & Separate / & 7 \\
2 & RH & 33 & Married / 2 & 13 \\
3 & AW & 25 & Married /2 & 7 \\
4 & IN & 43 & Married /2 & 12 \\
5 & PT & 29 & Married /1 & 12 \\
6 & MN & 28 & Married /2 & 8 \\
\hline
\end{tabular}

The result of measuring the behavior checklist of each participant's presented in several figures. The result of measuring behavior checklist indicates the existence of pattern uniformity. The pattern is a decrease in psychological burden when participants practice mindful parenting and increased psychological burden when participants do not practice mindful parenting. Fig. 5 showed that information.

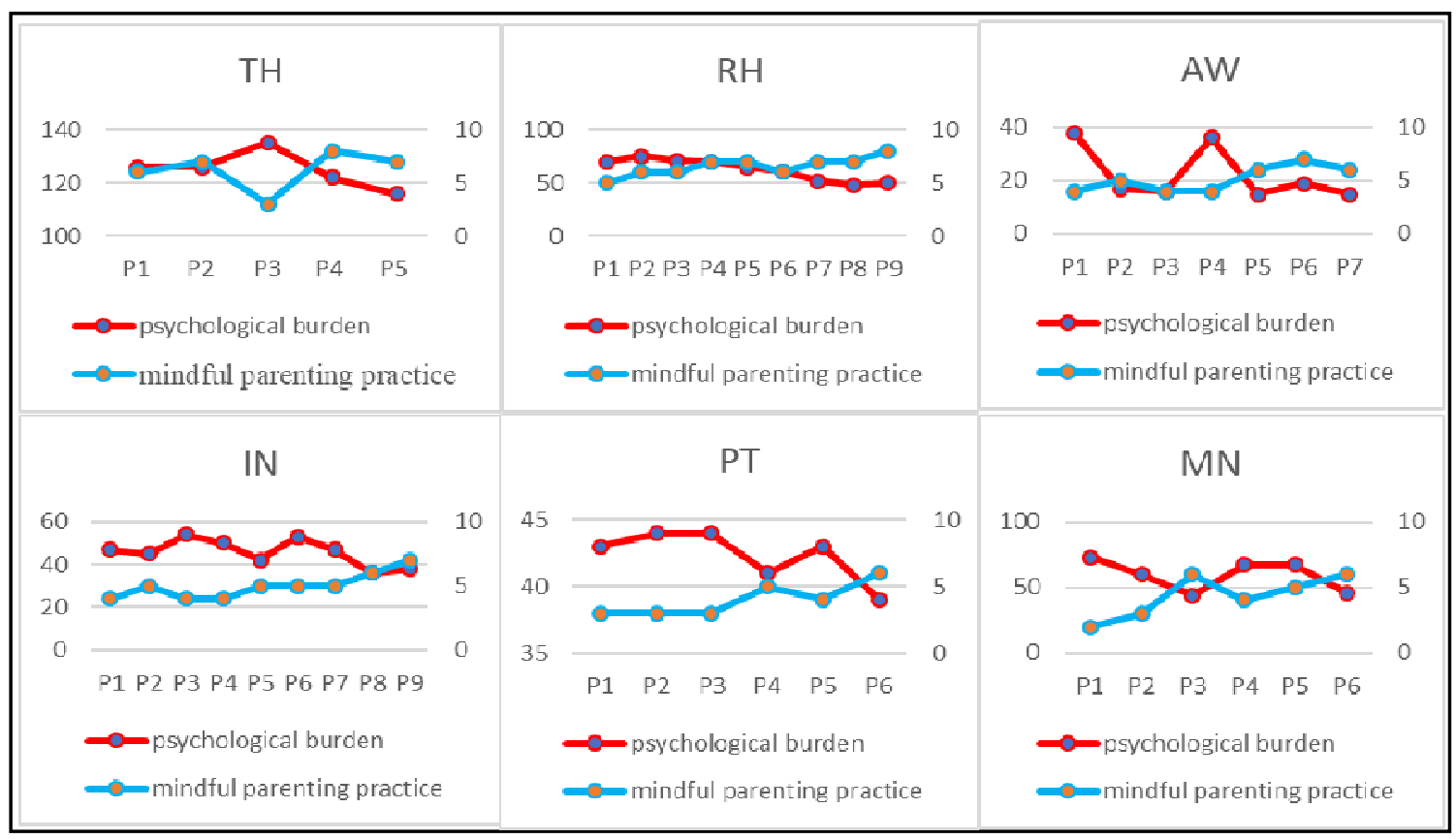

Fig. 5 Summary behavior checklist 


\section{Discussion}

The purpose of this study was to find out whether mindful parenting programs can reduce the psychological burden on mothers with children with cerebral palsy. The results showed significant changes in the score before and after treatment with the value of $z=-2.201(p=0.028 ; p<0.05)$. It means there is a significant difference between the psychological load of the mother and the child's cerebral palsy before and after treatment. So, it can be concluded that mindful parenting program can reduce the psychological burden on mothers with children cerebral palsy.

The effect size measurement results show $r=0.63(63 \%)$ which means it has a large effect (Cohen, 1988). The decrease in psychological burden is influenced by the emergence of cognitive awareness to see the events that exist in a way of view or positive meaning. Positive meaning is experienced by all participants. This condition is in line with the results of research that mindfulness can facilitate the creation of awareness to deal with problems (Donald \& Atkins, 2016), by helping to realize the mind-form owned (Moore \& Malinowski, 2009), so as to increase attention in decision making (Zeidan et al., 2010).

The influence of mindful parenting program is also shown with the analysis of the four aspects of the participants' psychological burden measurements all of which have decreased significantly. The role conflict decreased significantly with the value of $z=-2.207(p=0.027 ; p<0.05)$. Interviews resulted in the dynamics of the division of roles between participants and their work as well as families in the care of children during the participant to parenting mindful parenting program. Negative feelings decreased significantly with the value of $\mathrm{z}=-2.214(\mathrm{p}=0.027 ; \mathrm{p}<0.05)$. The development of participants by generating forgiveness, accepting circumstances, releasing negative experiences, establishing two-way communication to avoid misunderstandings, as well as managing emotions as part of learning. Mindfulness helps to have a new sense of response that can open up viewing events from different points of view (Compton, Hoffman, \& Compton, 2012), in tolerating thoughts, emotions and experiences (Baer, 2003).

Caregiver efficacy decreased significantly with the value of $\mathrm{z}=-2.214(\mathrm{p}=0.027 ; \mathrm{p}<0.05)$. Inability is closely related to low self-efficacy. Through the practice of mindfulness can see the potential possessed, show empathy to others, to be able to raise the sense of optimism that the self is able to live daily. This condition is in line with the study of that mindfulness through mediator attitude attention can improve self-efficacy in setting counseling (Greason \& Cashwell, 2009).

Guilt decreased significantly with the value of $\mathrm{z}=-2.032(\mathrm{p}=0.042 ; \mathrm{p}<0.05)$. Thinking about the past makes participants feel guilty. The results of the interviews revealed that the practice of mindful parenting along with the group's therapeutic factors helped participants learn to strengthen their gratitude and optimism in viewing life. Mindfulness attitude helps to see the conditions here and now (Shapiro et al., 2006). This condition helps participants to look back at an event with a new perspective and be able to distance themselves from the thoughts and emotions that accompany the event.

Based on manipulation check analysis, it was found that there was significant improvement of mindful parenting after treatment was given with $\mathrm{z}=-2.214(\mathrm{p}=0.027 ; \mathrm{p}<0,05)$. It means that manipulation checks see the immediate effect of manipulation of mindful parenting programs felt by participants. Some of the effects felt by participants are a sense of calm, comfort, some physical changes from increased appetite influences, and the use of mindful parenting skills that influence participants in responding to situations such as finding new meaning from a particular situation.

Based on demographic data, it is known that the psychological burden of TH and RH (pretest 1) participants tends to be highest. When viewed from background and activity notes, both participants experienced problems related to social support. TH with marital problems, RH with family support. Different conditions experienced by AW and IN with psychological burden tend to be low. AW and IN have strong social support from their husbands, families, and neighborhoods. Through this data, it is known that social support affects psychological burden. This is in line with research which suggests that social support (husbands, family, friends, healthcare) increases maternal adjustment of cerebral palsy children by leading to the ability to choose adaptive behaviors (Satih, 2004).

Through background and activity records, other conditions that may cause TH and RH to have high psychological burden are the factors of child self-reliance that make the focus of attention fully to the child. TH and RH have cerebral palsy children who can't be independent. Unlike the children AW, IN, PT and MN who can already be independent even follow the education in public schools. This condition is in 
line with the study who conveyed that one predictor of the psychological burden of the mother with a child's cerebral palsy is the high degree of disability experienced by the child (Muñoz-Marrón et al., 2013).

Based on the behavioral checklist data, it is known that there is a similar pattern to all participants. The pattern is a decrease in psychological burden when participants practice mindful parenting skills and vice versa. The participants continued to practice so that all participants reported benefiting from the practice of mindful parenting skills themselves. This condition is in line with research that states that the persistence of practicing mindfulness meditation resulted in a positive impact of mindfulness (Niemic, Rashid, \& Spinella, 2012).

Breathing meditation helps to calm the body and mind so as to create a broader perspective (KabatZinn, 2005). Benefits are obtained by all participants. The condition of RH participants feeling calm until they find the motivation to live life with sincerity. TH finds awareness that his attitude that prohibits children does not help children to be independent. AW realized that so far did not appreciate the support provided by the surrounding environment so as to make AW learn to respect others. Participants IN and PT find the benefits of being more able to appreciate the state of self and develop empathy to others. MN recognizes the management of the mind against the negative environmental advocacy response to be possible.

Participant gratitude meditation provides mixed benefits. Motivating RH to forgive others, helping TH think optimistically about the future of the child and his family, helping AW appreciate the great support of the family, helping MN to be more sensitive to the state of the environment. This condition is in line study that writing a thankful thing can increase life satisfaction and increase positive behaviour (Wood, Froh, \& Geraghty, 2010) Body scan meditation gives participants the benefit of consciousness that physical fatigue. This situation as obtained RH, AW, and PT. In line with research that body san helps to realize the condition of the body (Thompson \& Gauntlett-Gilbert, 2008). According Shapiro body scan is a way to develop a sense of love to yourself (Shapiro, 2009). Love to oneself is manifested by RH, AW, PT and $\mathrm{MN}$ by giving the body time to rest. Based on the results of development interviews, these four participants reported have better sleep quality.

Based on interviews, the virtue of loving kindness meditation is the skill which is most interested by all participants. According to research, meditators who practice love-loving meditation have less stress than non-practicing meditators (Kemper et al., 2015). This condition supports the results of research researchers that the more participants practice the meditation love goodness then the level of stress will be reduced because participants feel the calm and sense of happiness.

Some of the things that support the success of a program are participants' readiness to change with which is marked by participant openness and group involvement throughout the program (Corsini \& Wedding, 2010). The group therapy factor which support the change of participants are fostering positive expectations of the therapeutic elements, the presence of joint factors, group work, cathartic relief, and interpersonal learning (Yalom \& Leszcz, 2005) facilitated during the mindful parenting program. The mindful parenting program uses psychoeducation techniques which are the supporting factors that can be used to reduce psychological burden (Ambarawati, 2015)

Psychological burden is a cognitive meaning (Santrock, 2011). Through a non-judgment mindfulness attitude can help lead to increased self-efficacy to form realistic expectations (Brown \& Ryan, 2003). Increased self-control over emotions, empathy (Donald \& Atkins, 2016; Remmers, Topolinski, \& Koole, 2016), acceptance of childhood (Boyle et al., 2017; Ma \& Siu, 2016) the benefits of mindfulness that are also gained by research participants.

\section{Conclusion}

Results of this study indicate that mindful parenting program has an impact on the reduction of psychological burden on mothers with cerebral palsy children. This means that the hypothesis proposed in this study is acceptable. This result answers the research objective to reduce the psychological burden of the mother with a child's cerebral palsy through mindful parenting program. Based on the analysis of each aspect of psychological burden, it is concluded that the psychological burden of participants has changed in all aspects. This is supported by the improvement of the practice of significant mindfulness skills of the participants.

The limitations of the study stem from the threat of internal validity as well as the validity of statistical inference. Internal validity threats include selection, history, maturation, testing and the threat of 
statistical conclusions unreliability of treatment implementation (Shadish et al., 2002). The threat of selection occurs because this study involves only one treatment (experimental) group without a comparison group. The threat of history occurs because an event occurring at the same time as the treatment can produce observed effects. The threat of maturation occurs because of changes that occur naturally over time. Researchers overcome this threat by providing self-report media for the participants as learning information is done. The threat of testing occurs because in this study there is repetition of measurements with the same measuring instrument. The threat of statistical conclusion of unreliability of treatment implementation can be seen from the participant's notebook. Participants do not all practice parenting mindful exercises. Through the behaviour-checklist, the participants do not regularly apply the skills of mindful parenting in parenting. The threat of unreliability of treatment implementation in measurement can decrease the effect size (Shadish et al., 2002).

\section{References}

Alaee, N., Shahboulaghi F. M., Khankeh H., \& Kermanshahi, S. M. K. (2015). Psychosocial Challenges for Parents of Children with Cerebral Palsy: A Qualitative Study. Journal of Child and Family Studies, 24(7), $2147-54$.

Ambarawati, W. (2015). Efektifitas Program Psikoedukasi Kelompok Dalam Menurunkan Beban Psikologis Pada Family Caregiver Diabetes Melitus. Tesis, Universitas Gadjah Mada, Yogyakarta. Tidak diterbitkan.

Azwar, S. (2011). Reliabilitas dan Validitas (3rd ed.). Yogyakarta: Pustaka Pelajar.

Azwar, S. (2012). Penyusunan Skala Psikologi (2nd ed.). Yogyakarta: Pustaka Pelajar.

Baer, R. A. (2003). Mindfulness Training as a Clinical Intervention: A Conceptual and Empirical Review. Clinical Psychology: Science and Practice, 10(2), 125-43.

Bajraszewski, E., Carne, R., Kennedy, R., Lanigan, A., Ong, K., Randall, M., \& Reddihough, D. (2008). Celebral Palsy: An Information Guide for Parents (5th ed.). Melbourne: Royal Children's Hospital.

Barnett, D., Clements, M., Kaplan-Estrin, M., \& Fialka, J. (2003). Building New Dreams: Supporting Parents' Adaptation to Their Child with Special Needs. Infants \& Young Children, 16(3), 184-200.

Bax, M., Goldstein, M., Rosenbaum, P., Leviton, A., Paneth, N., Dan, B., Jacobsson, B., \& Damiano, D. (2005). Proposed Definition and Classification of Cerebral Palsy, April 2005. Developmental Medicine \& Child Neurology, 47(8), 571-76.

Beckung, E., Hagberg, G., Uldall, P., Cans, C., \& for Surveillance of Cerebral Palsy in Europe. (2008). Probability of Walking in Children With Cerebral Palsy in Europe. PEDIATRICS, 121(1), 187-92.

Berker, N., Yalçın, S., and Global HELP (Organization). (2010). The Help Guide to Cerebral Palsy. Washington: GLOBAL HELP.

Bögels, S. M., Hellemans, J., van Deursen, S., Römer, M., \& van der Meulen, R. (2014). Mindful Parenting: A Guide for Mental Health Practitioners. New York: Springer.

Bottcher, L. (2010). Children with Spastic Cerebral Palsy, Their Cognitive Functioning, and Social Participation: A Review. Child Neuropsychology, 16(3), 209-28.

Boyle, C. C. Stanton, A. L. Ganz, P. A., Crespi, C. M., and Bower, J. E. (2017). Improvements in Emotion Regulation Following Mindfulness Meditation: Effects on Depressive Symptoms and Perceived Stress in Younger Breast Cancer Survivors. Journal of Consulting and Clinical Psychology, 85(4), 397-402. 
Brehaut, J. C., Kohen D. E., Garner, R. E., Miller, A. R., Lach L. M., Klassen, A. F., \& Rosenbaum, P. L. (2009). Health among Caregivers of Children with Health Problems: Findings from a Canadian Population-Based Study. American Journal of Public Health, 99(7), 1254-62.

Brown, K. W., \& Ryan, R. M. (2003). The Benefits of Being Present: Mindfulness and Its Role in Psychological Well-Being. Journal of Personality and Social Psychology, 84(4), 822-48.

Brown, K. W., Ryan, R. M., \& Creswell, J. D. (2007). Mindfulness: Theoretical Foundations and Evidence for Its Salutary Effects. Psychological Inquiry, 18(4), 211-37.

Carlson, L., Rouleau, C. R., \& Garland, S. N. (2015). The Impact of Mindfulness-Based Interventions on Symptom Burden, Positive Psychological Outcomes, and Biomarkers in Cancer Patients. Cancer Management and Research 121.

Carmody, J., \& Baer, R. A. (2008). Relationships between Mindfulness Practice and Levels of Mindfulness, Medical and Psychological Symptoms and Well-Being in a Mindfulness-Based Stress Reduction Program. Journal of Behavioral Medicine 31(1):23-33.

Centers for Disease Control and Prevention. (2014). "Facts | Cerebral Palsy | NCBDDD | CDC." Retrieved May 25, 2016 from http://www.cdc.gov/ncbddd/cp/facts.html

Chen, H-M., Huang, M-F., Yeh, Y-C., Huang, W-H., \& Chen C-S. (2015). Effectiveness of Coping Strategies Intervention on Caregiver Burden among Caregivers of Elderly Patients with Dementia: Intervention for Dementia Caregivers. Psychogeriatrics, 15(1), 20-25.

Cohen, J. (1988). Statistical Power Analysis for the Behavioral Sciences (2nd ed.). New York: Academic Press.

Colver, A., Fairhurst, C., and Pharoah, P. O. D. (2014). Cerebral Palsy. The Lancet 383(9924):1240-49.

Compton, W. C., Hoffman, E., \& Compton, W. C. (2012). Positive Psychology: The Science of Human Flourishing (2nd ed.). Australia ; Belmont, CA: Wadsworth, Cengage Learning.

Corsini, R. J., \& Wedding, D., eds. (2010). Current Psychotherapie (9th ed.). Australia: Brooks/Cole, Cengage Learning.

Davis, E., Shelly, A., Waters, E., Boyd, R., Cook, K., \& Davern, M. (2010). The Impact of Caring for a Child with Cerebral Palsy: Quality of Life for Mothers and Fathers. Child: Care, Health and Development, 36(1), 63-73.

Donald, J. N., \& Atkins, P. W. B. (2016). Mindfulness and Coping with Stress: Do Levels of Perceived Stress Matter?. Mindfulness, 7(6), 1423-36.

Duncan, (2007). Assessment of Mindful Parenting among Families of Early Adolescents: Development and Validation of the Interpersonal Mindfulness in Parenting Scale. Pennsylvania State University.

Elliott, T. R., \& Shewchuk, R. M. (2004). Family Adaptation in Illness, Disease, and Disability. Pp. 379-403 in Handbook of clinical health psychology: Volume 2. Disorders of behavior and health., edited by J. M. Raczynski and L. C. Leviton. Washington: American Psychological Association.

Fernández-Alcántara, M., García-Caro, M. P., Laynez-Rubio, C., Pérez-Marfil, M. N., Martí-García, C., Benítez-Feliponi, Á., Berrocal-Castellano, M., \& F. Cruz-Quintana. (2015). Feelings of Loss in Parents of Children with Infantile Cerebral Palsy. Disability and Health Journal, 8(1), 93-101.

Field, A. P. (2009). Discovering Statistics Using SPSS (3rd ed.). Los Angeles: SAGE Publications. 
Glenn, S., Cunningham, C., Poole, H., Reeves, D., \& Weindling, M. (2009). Maternal Parenting Stress and Its Correlates in Families with a Young Child with Cerebral Palsy. Child: Care, Health and Development, $35(1), 71-78$.

Greason, P. B., \& Cashwell, C. S. (2009). Mindfulness and Counseling Self-Efficacy: The Mediating Role of Attention and Empathy. Counselor Education and Supervision, 49(1), 2-19.

Grootenhuis, M. A., \& Bronner, M. B. (2009). Paediatric Illness! Family Matters. Acta Paediatrica (Oslo, Norway: 1992), 98(6), 940-41.

John, R., Hennessy, C. H., Dyeson, T. B., \& Garrett, M. D., (2001). Toward the Conceptualization and Measurement of Caregiver Burden among Pueblo Indian Family Caregivers. The Gerontologist, 41(2), 210-19.

Kabat-Zinn, J. ( 2005). Full Catastrophe Living: Using the Wisdom of Your Body and Mind to Face Stress, Pain, and Illness. Delta trade pbk. reissue. New York, N.Y: Delta Trade Paperbacks.

Kabat-Zinn, J. (2013). Full Catastrophe Living: Using the Wisdom of Your Body and Mind to Face Stress, Pain, and Illness (Revised and Updated Edition). New York: Bantam Books Trade Paperback.

Kasuya, R., Polgar-Bailey P., \& Takeuchi R. (2000). Caregiver Burden and Burnout: A Guide for Primary Care Physicians. Postgraduate Medicine, 108(7), 119-23.

Kemper, K. J., Powell, D., Helms, C. C., \& Kim-Shapiro, D. B. (2015). Loving-Kindness Meditation's Effects on Nitric Oxide and Perceived Well-Being: A Pilot Study in Experienced and Inexperienced Meditators. EXPLORE: The Journal of Science and Healing, 11(1), 32-39.

Knapp, T. R. (2016). Why Is the One-Group Pretest-Posttest Design Still Used? Clinical Nursing Research 25(5), 467-72.

Koeswardani, T. E. (2011). Terapi Pemaafan Untuk Menurunkan Beban Subjektif Pendamping Penderita Skizofrenia. Tesis, Universitas Gadjah Mada, Yogyakarta. Tidak diterbitkan.

Ma, Y., \& Siu, A. F. Y. (2016). A Qualitative Exploration of an Eight-Week Mindful Parenting Program for Parents. Republic of Korea: Korean Counseling Association, 6(2), 87-100.

Marriott, A. (2000). Effectiveness of Cognitive--Behavioural Family Intervention in Reducing the Burden of Care in Carers of Patients with Alzheimer's Disease. The British Journal of Psychiatry, 176(6), 557-62.

Marsden, E., \& Torgerson, C.J. (2012). Single Group, Pre- and Post-Test Research Designs: Some Methodological Concerns. Oxford Review of Education, 38(5), 583-616.

Martín-Carrasco, M., Martín, M. F., Valero, C. P., Millán, P. R., García, C. I., Montalbán, S. R., Vázquez, A. L. G., Piris, S. P., \& Vilanova, M. B. (2009). Effectiveness of a Psychoeducational Intervention Program in the Reduction of Caregiver Burden in Alzheimer's Disease Patients' Caregivers. International Journal of Geriatric Psychiatry 24(5), 489-99.

Mendenhall, A., \& Mount, K. (2011). Parents of Children with Mental Illness: Exploring the Caregiver Experience and Caregiver-Focused Interventions. Families in Society: The Journal of Contemporary Social Services, 92(2), 183-90.

Moore, A., \& Malinowski, P. (2009). Meditation, Mindfulness and Cognitive Flexibility. Consciousness and Cognition, 18(1), 176-86.

Morris, C. (2007). Definition and Classification of Cerebral Palsy: A Historical Perspective. Developmental Medicine \& Child Neurology, 109, 3-7. 
Muñoz-Marrón, E., Redolar, D., Boixadós, M., Nieto, R.., Guillamón, N., Hernández E., \& Gómez, B. (2013). Burden on Caregivers of Children with Cerebral Palsy: Predictors and Related Factors. Universitas Psychologica, 12(3), 767-777.

Myers, J. E. (2003). Coping with Caregiving Stress: A Wellness-Oriented, Strengths-Based Approach for Family Counselors. The Family Journal: Counseling and Therapy for Couples and Families, 11(2), 15361.

Niemic, R. M., Rashid, T., \& Spinella, M. (2012). Strong Mindfulness : Integrating Mindfulness and Character Strenghts. Journal of Mental Health Counseling, 34(3), 240-53.

Olawale, O., Deih, A., \& Yaadar, R. (2013). Psychological Impact of Cerebral Palsy on Families: The African Perspective. Journal of Neurosciences in Rural Practice, 4(2), 159.

Ones, K. (2005). Assessment of the Quality of Life of Mothers of Children with Cerebral Palsy (Primary Caregivers). Neurorehabilitation and Neural Repair, 19(3), 232-37.

Pakdaman, S. N. (2014). Susan Bögels and Kathleen Restifo: Mindful Parenting: A Guide for Mental Health Practitioners. Mindfulness, 5(4), 467-70.

Park, M. S., Kim, S. J., Chung, C. Y., Kwon, D. G., Choi, I. H., \& Lee K. M. (2011). Prevalence and Lifetime Healthcare Cost of Cerebral Palsy in South Korea. Health Policy, 100(2-3), 234-38.

Prisco, V., Del Vecchio, V., Luciano, M., Giacco, D., Sampogna, G., Del Gaudio, L., De Rosa, C., \& Fiorillo, A. (2012). P-523 - Efficacy of Psychoeducational Family Intervention for Depression. European Psychiatry, 27(1), 1.

Raina, P. (2005). The Health and Well-Being of Caregivers of Children with Cerebral Palsy. PEDIATRICS, 115(6), 626-36.

Remmers, C. Topolinski, S., \& Koole, S. L. (2016). Why Being Mindful May Have More Benefits Than You Realize: Mindfulness Improves Both Explicit and Implicit Mood Regulation. Mindfulness, 7(4), 829-37.

Rethlefsen, S. A., Ryan, D. D., \& Kay, R. M. (2010). Classification Systems in Cerebral Palsy. Orthopedic Clinics of North America, 41(4), 457-67.

Ribeiro, M. F. M., Sousa, A. L. L., Vandenberghe, L., \& Porto, C. C. (2014). Parental Stress in Mothers of Children and Adolescents with Cerebral Palsy. Revista Latino-Americana de Enfermagem, 22(3), 440-47.

Richards, C. L., \& Malouin, F. (2013). Cerebral Palsy. In Handbook of Clinical Neurology. Pp. 183-9. Vol. 111. Elsevier.

Rizky, M. (2017). Program ‘Mindful Parenting' Untuk Meningkatkan Kesejahteraan Subjektif Ibu Yang Memiliki Anak Retardasi Mental. Tesis, Universitas Gadjah Mada, Yogyakarta. Tidak diterbitkan.

Rojahn, J., Schroeder, S. R., \& Hoch, T. A. (2008). Self-Injurious Behavior in Intellectual Disabilitie (1st ed.). Amsterdam: Elsevier.

Rosenbaum, P., Paneth, N., Leviton, A., Goldstein, M., Bax, M., Damiano, D., Dan, B., \& Jacobsson, B. (2007). A Report: The Definition and Classification of Cerebral Palsy April 2006. Developmental Medicine \& Child Neurology, 49, 8-14.

Santrock, J. W. (2011). Child Development (13th ed.). New York, NY: McGraw-Hill Humanities.

Satih, S. (2004). Hubungan Antara Kecenderungan Depresi Ibu Yang Memiliki Anak Cerebral Palsy Dengan Efikasi Diri Dan Dukungan Sosial. Tesis, Universitas Gadjah Mada, Yogyakarta. Tidak diterbitkan. 
Shadish, W. R., Cook, T. D., \& Campbell, D. T. (2002). Experimental and Quasi-Experimental Designs for Generalized Causal Inference. Boston: Houghton Mifflin.

Shapiro, S. L. (2009). The Integration of Mindfulness and Psychology. Journal of Clinical Psychology, 65(6), 555-60.

Shapiro, S. L., Carlson, L. E., Astin, J. A., \& Freedman, B. (2006). Mechanisms of Mindfulness. Journal of Clinical Psychology, 62(3), 373-86.

Thompson, M., \& Gauntlett-Gilbert, J. (2008). Mindfulness with Children and Adolescents: Effective Clinical Application. Clinical Child Psychology and Psychiatry, 13(3), 395-407.

WHO. (2011). World Report on Disability. Retrieved May 29, 2016 from whqlibdoc.who.int/hq/2011/WHO_NMH_VIP_11.01_eng.pdf?ua=1

Wongpakaran, N., Wongpakaran, T., Wedding D., \& Gwet. K. L. (2013). A Comparison of Cohen's Kappa and Gwet's AC1 When Calculating Inter-Rater Reliability Coefficients: A Study Conducted with Personality Disorder Samples. BMC Medical Research Methodology, 13(1).

Wood, A. M., Froh, J. J., \& Geraghty, A. W. A. (2010). Gratitude and Well-Being: A Review and Theoretical Integration. Clinical Psychology Review, 30(7), 890-905.

Woodgate, R. L., Edwards, M., \& Ripat, J. (2012). How Families of Children with Complex Care Needs Participate in Everyday Life. Social Science \& Medicine, 75(10), 1912-20.

Yalom, I. D., \& Leszcz, M. (2005). The Theory and Practice of Group Psychotherapy (5th ed.). New York: Basic Books.

Zaretsky, H. H., Richter, E. F., \& Eisenberg, M. G. (2005). (Eds). Medical Aspects of Disability: A Handbook for The Rehabilitation Professional (3rd ed.). New York, NY: Springer Pub.

Zeidan, F., Johnson, S. K., Diamond, B. J., David, Z., \& Goolkasian, P. (2010). Mindfulness Meditation Improves Cognition: Evidence of Brief Mental Training. Consciousness and Cognition, 19(2), 597-605. 